\title{
What Aristotelian Decisions Cannot Be
}

Jozef Müller

Ancient Philosophy 2016, vol. 36, issue 1, 173-195.

This is a preprint.

\section{Introduction}

In Aristotle's Ethical Theory, W.F.R. Hardie writes that, '... while we must ask what Aristotle means by prohairesis, we must not assume that a definite answer can be given. A definite answer would be possible only if Aristotle had himself made and accepted the distinctions which, in asking what he meant, we have ourselves assumed'. ${ }^{1}$ This paper is an

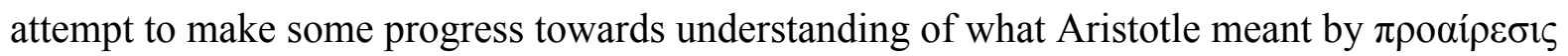
(decision) $)^{2}$ by arguing that Aristotelian decisions cannot be (or cannot just be) what we usually or often take them to be.

It might be thought that Hardie's worry has lost much of its relevance since there has

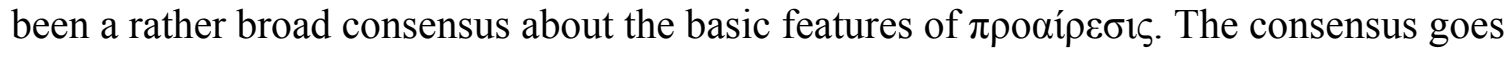

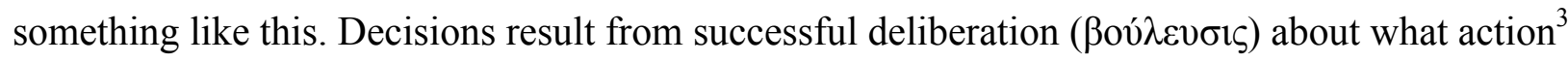
would best promote an end which is desired in virtue of its being conceived of as good by the agent (EN 1113b4-7). An end of this sort is the object of a specific kind of desire (ö $\rho \xi \xi 1 \varsigma$ ) that

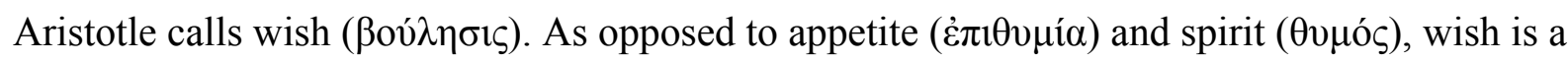
rational kind of desire. Although the distinction between rational (i.e., wish) and non-rational desires (i.e., appetite and spirit) is well-documented in Aristotle's writings, ${ }^{4}$ it is difficult to give

\footnotetext{
${ }^{1}$ Hardie 1980, 164.

${ }^{2}$ There is no universal agreement about a suitable translation of $\pi \rho \alpha^{\prime} i^{\prime} \varepsilon \sigma \iota \varsigma$. The usual translations in the literature are 'choice', 'deliberate choice', or 'decision'. In this paper, I stick to 'decision'.

${ }^{3}$ Insofar as his technical concept of decision is concerned, Aristotle is explicit both in the $E N(3.1-5)$ and the $E E$ (2.6-11) that they are choices of actions that one can immediately engage in without needing to deliberate further about how to do so (e.g., 1113a10-12). This technical conception of decision should be distinguished from choices

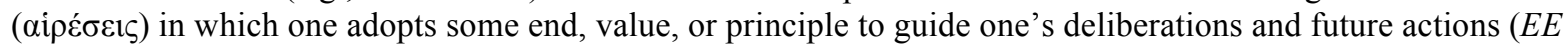
1215b36, 1216a15, 1249a24-b23; EN 1104b30-35). As opposed to decision, such choice need not be reached by rational calculation (EE 1226b7).

${ }^{4}$ For the division of desires into rational and non-rational ones, see DA 432b5-6; Rhet. 1368b37-69a7; and Top. 126a3-13. In the $E N$, the division is not made explicit, but it is clearly implied at many places (e.g., 1102b13-a3 or $1111 \mathrm{a} 27-\mathrm{b} 13)$. For the divisions of desire (ő $\rho \xi \xi 1 \varsigma)$ into three kinds, see especially $D A 414 \mathrm{~b} 2 ; E E 1223 \mathrm{a} 27$ and $1225 \mathrm{~b} 25$.
} 
an uncontroversial description of it. ${ }^{5}$ In general, appetite and spirit are desires that are aroused by perceiving something in a pleasant or painful way. They belong to the perceptual faculty ( $D A$

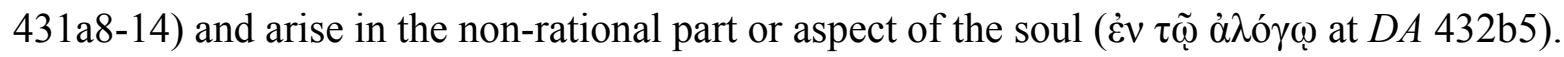
Although human non-rational desires are rational in a way since they can listen to reason and even be, in some way, persuaded by it (EN 1102b29-1103a4), they nevertheless remain to some extent independent of reason. It is their distinctive feature that one can come to desire something (i.e., come to have an appetite or a spirited desire for something) independently of whether one also believes or judges that one should desire it. ${ }^{6} \mathrm{Wish}$, however, originates in the reasoning part

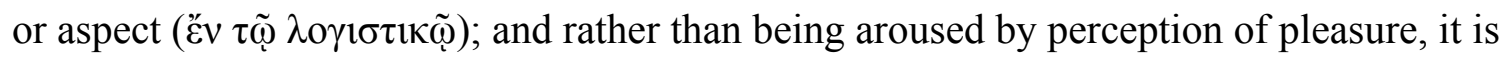
aroused by thinking or judging that something is good for oneself (EN 1113b23-27). It is thus a kind of desire that is not found among animals other than human beings since only the ability to think or judge things in terms of their goodness. ${ }^{7}$ Since decisions result from wish and deliberation, they are based solely rational cognition and rational volition, and are thus, to use Richard Sorabji's expression 'a rational thing'.

\footnotetext{
${ }^{5}$ There is no universal consensus about, on the one hand, the extent and the way in which human perceptual cognition and non-rational volition (i.e., appetite and spirit) is integrated with rationality and, on the other hand, the extent and the way in which rational volition (i.e., wish) is or can be consistently thought to be, a genuine desire rather than, say, a mere preference. Consequently, there are controversies about the precise way in which one is supposed to understand Aristotle's claim that desire (or the desiderative faculty) is in some way unified ( $D A$ 433a21). For an overview of some of these controversies and problems, see Moss 2014; Pearson 2012, 62-88, 170226; and Corcilius 2008, 160-207.

${ }^{6}$ This is clear from the case of lack of control (akrasia): the uncontrolled person has an appetite for doing or having something (e.g., $E N$ 1147a33; DA 433a1-8 and 433b5-12) that he does not think he should do or have (EN 1146b23). Consequently, so he has an appetite for doing or having something that he does not wish to do or have (EN 1136b69; $D A 433 \mathrm{~b} 5-13)$. Although the case of spirit is more complicated, it too can arise independently of reason (1145b20, 1149a25-1149b4). Note that the fact that an appetite or spirit can arise independently of one's beliefs or judgments does not necessarily mean that when they do so arise, they are opposed to one's beliefs or judgments.

${ }^{7}$ Non-rational desires, in the sense used above, are not irrational desires. They are desires that need not be, and often are not, produced or directly controlled by reasoning processes. Irrational desires, on the other hand, are desires that it does not make sense for one to have, either from a subjective point of view (as when one sees every reason not to desire something and no reason to desire it but desires it nevertheless), or from an objective point of view (as when one's having a certain desire is in some way absurd or unintelligible). Thus an animal might well have only nonrational desires but it need not have any irrational desires. Although the word $\alpha \lambda \lambda_{0} \gamma o \varsigma$ can be used to mean irrational or absurd (e.g., Plato, Theat. 203d), Aristotle's use of it, in the relevant contexts, is in the sense of non-rational (e.g., EN 1102a26-b1103a3; EE 1221b31, 1247b19; Pol. 1334b21; Rhet. 1369a2-1370a19). Similarly, rational desires in the sense used here are not desires that it is always good to have or that it always makes sense to have, but desires that are produced or controlled by reasoning processes.

${ }^{8}$ Sorabji 1980, 202.
} 
In order to complete this basic picture, ${ }^{9}$ one needs to identify the precise role and nature of wish and deliberation in the process of generating decisions. The trouble is that no matter what understanding one has of wish or deliberation, the resulting picture of decision - based on the basic idea of decision as a 'rational thing' - is difficult to square with the various roles that Aristotle assigns to it. Perhaps the most striking example of an interpretative problem of this sort is Aristotle's definition of the best the state of one's non-rational desires and feelings (i.e., of

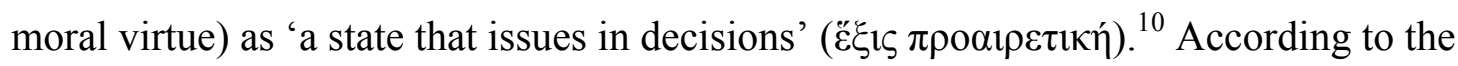
definition, we are supposed to think of decisions as in some way resulting from non-rational desires. But according to the basic conception of decision introduced above, decisions are the results of only rational states and processes (i.e., wish and deliberation). So we have both two incompatible claims about decision, as well as a problem of fit between the definiendum and the definiens. The most common strategies to deal with this problem include reworking the conception of moral virtue ${ }^{11}$ or reworking the conception of wish. ${ }^{12}$ However, most interpretative attempts still end up with the basic problem of defining excellence of character (which is at least prominently constituted by the state of one's non-rational desires) as a state that issues in decisions (which are not based on non-rational desires).

In this paper, my interest lies in this basic idea or agreement about what kind of thing decision is rather than in the many different ways in which the basic picture has been worked out. I argue that although some features of the basic picture are correct, Aristotelian decisions must sometimes include non-rational desires and that, therefore, they cannot be conceived of as based just on wish and deliberation. The correct features are:

\footnotetext{
${ }^{9}$ The view can be traced back to Anscombe 1965. The widespread acceptance of the basic idea of Anscombe's interpretation makes it impractical to list all its supporters, but see Cooper 1975, n48; Gourinat 2002; Irwin 1988, 336-8; Kenny 1979, 96-100; Lorenz 2009; Mele 1981; Reeve 1992, 87-88; Segvić 2009.

${ }^{10} E N 1106 \mathrm{~b} 36-1107 \mathrm{a} 2$. It is not clear what would be the adequate translation of this expression. This is partly a

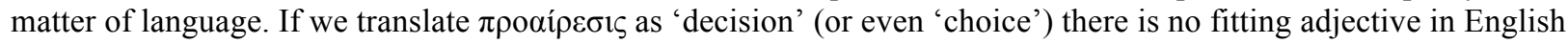
that we could derive to capture the meaning of the -ikos ending (other than 'decisive', which is unfitting for this purpose) which conveys, roughly, the idea of 'being capable of...'. The following translations can be found in some of the more used translations. Irwin translates 'a state that decides', Rowe 'a disposition issuing in decisions', Ross 'a state concerned with choice', Gauthier and Jolif 'un état habituel qui dirige la décision', Bodéüs 'un état décisionnel', Dirlmeier 'eine feste, auf Entscheidung hingeordnete Haltung'. For a discussion of this issue see Lorenz 2009, 196-197.

${ }^{11}$ A well-known strategy to alleviate the worry is to make practical wisdom ( $\left.\varphi \rho o ́ v \eta \sigma ı \varsigma\right)$ a part of the excellence of character. A view of this sort is argued in Lorenz 2009.

${ }^{12}$ One such strategy is to loosen the link between wish and eudaimonia in such a way that wishes remain to be based on (at least potential) reasons but they need not be connected (via those reasons) to any conception of goodness or eudaimonia. For views of this sort, see Broadie 1991, 107; and Charles 1984, 152.
} 
1) the explicit connection of decisions to deliberation (e.g., $N E$ 11123a3-9);

2) the idea that in deciding for an action one does so always explicitly for a reason (e.g., EE 1226b21-30);

3) and the idea that decisions have something to do with rational desires (NE 1113a1314 and 1113b4-6).

If my argument is correct, then any exegetical account of Aristotle's notion of decision must be able to accommodate this feature. In fact, given that it would show that decisions can in some way combine rational and non-rational desires or elements, the argument should inspire us to rethink the ways in which Aristotle's views about the divisions and connections between rational and non-rational cognition and desires are usually interpreted. Although I do not offer a positive account of what these connections and, in fact, what Aristotelian decisions are (and so also no positive interpretation of the definition of moral virtue mentioned above), my argument points to certain features that such general account of decision should have.

The argument concentrates on a very specific sort of decisions - decisions in which one chooses to engage in some harmless pleasures, such as listening to a piece of music, or having a cup of tea. Admittedly, these sorts of decisions are not at the center of Aristotle's ethical writings. This might explain why they have not been, to my knowledge, discussed in secondary literature, unless in passing. ${ }^{13}$ But harmless pleasures are nevertheless mentioned and discussed by Aristotle both in the EN (e.g., 4.8 and 10.6), as well as in the Politics' discussion of the ideal constitution. My aim is to explore what thinking about them can contribute to our understanding of Aristotle's theory or conception of decision.

\section{Aristotle on the Value of Harmless Pleasures}

Although Aristotle is not a hedonist, he does not view pleasure as something to be avoided. On the contrary, he argues that even if pleasure is not the good, it is nevertheless a good (EN 7.12-13 and 10.3). In fact, pleasure is good in itself and it is pursued by people as such (e.g., EN 1097b2-5). ${ }^{14}$ In most cases, these claims are not problematic for Aristotle's theory of eudaimonia as something distinct from pleasure (whether this is to be understood in the exclusive or inclusive way), since most pleasures fail to satisfy the various criteria for being the

\footnotetext{
${ }^{13}$ Irwin 1988, 332.

${ }^{14}$ See Shields 2011 for a discussion of the relationship between pleasure and goodness.
} 
human good (such as completeness, self-sufficiency, function argument, and so on). However, there is a class of pleasures that seems to satisfy at least some of those conditions. These pleasures are characterized by the fact that they do not lead (unless accidentally) to any further good or bad consequences. Examples of such pleasant but harmless activities include playing games (say, backgammon), singing a song while showering, or enjoying a cup of coffee in the afternoon. ${ }^{15}$ Both Plato and Aristotle recognized the existence of such pleasant activities, calling them 'harmless pleasures'. Plato mentions them explicitly twice. They are first alluded to in the Republic (357b-c) as the sole example of things that are good for their own sake but not for anything else. They are those good things from which nothing other results than the delight of having them. They reappear in the Laws (667d-e), where he says that they are pleasures, such as amusements ( $\pi \alpha 1 \delta 1 \alpha i)$, that have no particular harmful or good effect. This is followed by an argument in which the Athenian claims that since harmless pleasures lack any correctness and usefulness, the virtuous agent should not go for them since there are always better things to do comparatively (668a-b), namely those pleasures that offer correctness or usefulness.

Aristotle's own conception of harmless pleasures in Politics 8.5 and EN 10.6 closely follows Plato's conception - the paradigmatic examples of harmless pleasures are amusements. They have no future consequences for which they could be chosen but they are chosen for their own sake (EN 1176b10-11; Pol. 1339a16-17; 1339b24-41). ${ }^{16}$ However, as we shall see, Aristotle differs from Plato in his assessment of the value of such pleasures. I will attend to his assessment shortly. For the moment, however, I focus on the conditions for the human good that harmless pleasures satisfy. These are completeness and self-sufficiency. Since pleasure is a good and a good which is good in itself, it follows that harmless pleasures are also good in themselves. Hence, they are also choiceworthy in their own right. But since they are harmless, they are not choiceworthy for the sake of anything else:

\footnotetext{
${ }^{15}$ There is a nice example of harmless pleasure in Lars Gustafsson's novel The Death of a Beekeeper: 'It is raining every day now, and I stay in bed a little longer than usual in the winter darkness simply because it is pleasant to hear the rain falling on the roof'.

${ }^{16}$ Although the contexts in which amusements and harmless pleasures appear EN 10.6 and Pol. 8.5 are different, in both places they share characteristics that seem to me sufficient to warrant treating the two passages as holding the same view about them: they are chosen by people in their own right and not for any consequences (since they do not appear to have any) and they bear resemblance to (and so are often confused with) the ultimate end (i.e., eudaimonia).
} 


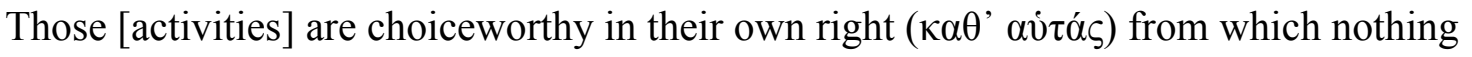

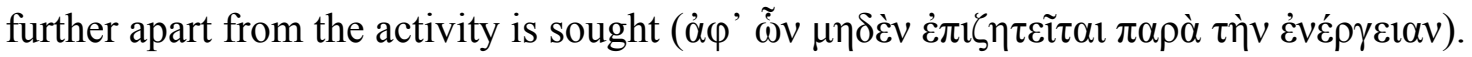
Actions in accord with virtue seem to be of that sort since fine and excellent actions are

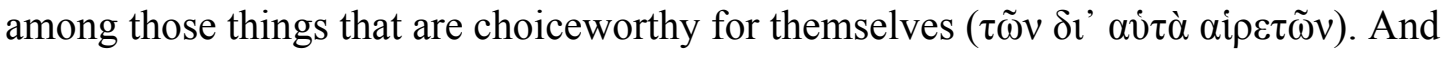
pleasant amusements ( $\alpha i \dot{\eta} \delta \varepsilon i \tilde{\alpha} \tau \tilde{\imath} \nu \pi \alpha 1 \delta i \tilde{\omega} v$ ) also [seem to be such] as they are not chosen for other ends [but themselves]; for people get actually more harm than benefit from [engaging in] them, as [while they do so] they are neglecting their bodies and possessions. ${ }^{17}$ (EN 1176b8-13).

Thus, according to Aristotle's definition of completeness at EN 1097a30-1097b2, ${ }^{18}$ they are complete without qualification. At least some harmless pleasures are also self-sufficient, at least in the sense in which self-sufficiency is explained by Aristotle at EN 1177a27-77b4. According to the passage, an activity is self-sufficient if its pursuit does not require others to be involved either as partners or recipients. Some harmless pleasures are clearly of this kind (say, listing to the rain outside or playing solitaire). It would appear, then, that harmless pleasures satisfy both completeness and self-sufficiency. Thus, as Aristotle notes, pleasant amusements bear a certain resemblance to happiness (EN 1176b7-20; Pol. 1339b31-41). This resemblance leads many people to conclude that happiness just is a life aimed at or focused on various activities of pleasant amusements.

Aristotle has three principal arguments against this conclusion. First, 'amusement appears stupid and excessively childish' and happy life 'is a life involving serious actions' (1176b311177a2). Second, amusements are accessible to anybody, even to the worst of persons, but happiness is something that we all agree cannot and is not shared or achieved just by anybody (1177a2-7). Third, although harmless pleasures and amusements are choiceworthy in their own right, they are so only because we cannot toil continuously and are sometimes in need of relaxation (1176b30-35). Aristotle concludes that 'the happy life seems to be a life in accord with virtue, which is a life involving serious action, and not consisting in amusement' (1177a1-3). ${ }^{19}$

\footnotetext{
${ }^{17}$ The neglect is an accidental result of engaging in pleasant amusements rather than a consequence implied by their nature.

18 '...what is complete without qualification is that which is always choiceworthy in itself and never because of something else'.

${ }^{19}$ Cf. Kraut 1989, 164-166 as well as the notes and references in Gauthier and Jolif 1970, ad loc.
} 
As I have mentioned, Plato thought (on the basis of arguments not dissimilar from Aristotle's) that harmless pleasures are to be avoided - virtuous people have better things to do. Aristotle, however, maintains that pleasant amusements have a function in a good life, and that all people (including virtuous agents) sometimes choose them and when they do, they choose them for their own sake:

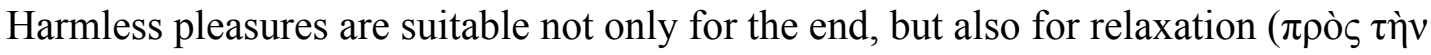
$\dot{\alpha} v \alpha \dot{\pi} \pi \alpha v \sigma v)$. But since it rarely happens that people achieve the end, whereas they do frequently relax and make use of amusements ( $\chi \rho \tilde{\omega} \nu \tau \alpha \imath \tau \alpha \tilde{i} \varsigma \pi \alpha 1 \delta 1 \alpha \tilde{i} \varsigma$ ), not only because

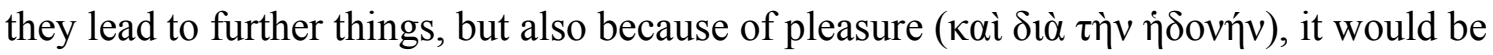

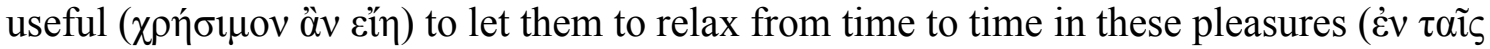

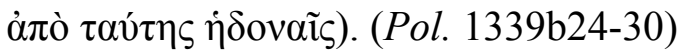

In passage Aristotle asserts, quite explicitly, that harmless pleasures (which prominently include amusements), are often undertaken by people for their own sake (rather than because they have any further results). He goes on to say that because these pleasures are quite suitable for relaxation, we should, from time to time, let people indulge in them so that they can relax. In the context, this claim concerns all people, including virtuous agents. But this is surprising since it is not clear why the virtuous agent would do as the passage suggests. On the one hand, harmless pleasures are not among the pleasures that are constitutive of eudaimonia. As Aristotle says, they are neither fine (kalos) nor serious (spoudaios) and so they are not of the right sort to be included in the human good (EN 1176b29-77a10). On the other hand, since they do not have, by definition, any further consequences, they also cannot be instrumentally related to eudaimonia.

It would seem that the virtuous agent should never choose them, just as Plato thought. Rather, he should prefer other, more valuable things or activities which do contribute to his happiness. After all, is the virtuous agent not supposed to organize his life in such a way that all she does is grounded in and aimed at her conception of eudaimonia? ${ }^{20}$ Yet, this is clearly not Aristotle's view. Harmless pleasures, such as amusements, are part of life and they are so even

\footnotetext{
${ }^{20}$ Most explicitly at EN 1177b33-34, and EE 1214b7-14. See also EN 1094a18-27; 1097a30-97b6; and 1176a30-34.
} 
for the virtuous agent. How are we, then, supposed to reconcile Aristotle's claim that there is a role for harmless pleasures in a good or virtuous life with the fact that they are neither instrumental to nor constitutive of eudaimonia?

One could object that although harmless pleasures might not be constitutive of or instrumental to happiness under that description (as harmless pleasures), they are nevertheless constitutive of it de re. But in EN 10.6 Aristotle is not saying that we can engage in the kind of activities that are mere harmless amusements provided we do not engage in them under that description - he thinks such activities themselves (under whatever description) are not part of eudaimonia. It is notable that this problem arises whether one assumes the inclusive or the exclusive interpretation of eudaimonia. ${ }^{21}$ On either interpretation, pleasant amusements are not among the things that are either instrumental to or part of eudaimonia. Consequently, even though it is clear that Aristotle thinks that all people, including virtuous agent do engage in these sorts of activities, it is not clear how to reconcile this view with his apparent commitment that the virtuous agent does everything for the sake of eudaimonia. One could, of course, stretch the inclusive interpretation so as to include pleasant amusements, but this move would both contradict what Aristotle says about them in $E N$ 10.6, as well as run the danger of making Aristotle's conception of eudaimonia lose much of its explanatory and practical power. On a view of this sort, eudaimonia would cease to be, or cease to provide, a criterion for organizing one's life around what is truly good and worthwhile (EN 1094a23-26) and become a mere title

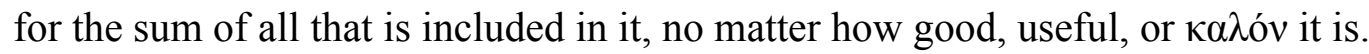

We can start thinking about these questions by attending to several passages in Politics 8.5. The chapter is devoted to the investigation of the place of music in education. Aristotle is particularly interested in determining whether music is to be engaged in (a) for the sake amusement or relaxation in the same way in which we engage in sleep, drinking or dancing i.e., as in something merely pleasant and not serious (Pol. 1339a15-25); or (b) for the sake of virtue as a part of one's education ( $\pi \alpha 1 \delta \varepsilon i ́ \alpha)$, enabling us to enjoy things in the right way; or (c)

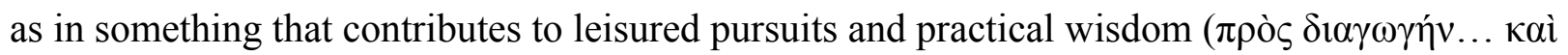
$\pi \rho o ̀ \varsigma \varphi \rho o ́ v \eta \sigma \mathrm{v})$.

\footnotetext{
${ }^{21}$ Examples of well-known inclusive interpretations include Ackrill 1974, Irwin 1985, Whiting 1986, Cooper 1987, Crisp 1994, or Long 2011. Examples of well-known exclusive or dominant interpretations include Kraut 1989, Kenny 1992, and Richardson Lear 2004.
} 
As he claims, music shares in all three categories. But it is his explanation of music's suitability for pleasant amusement that is especially interesting for our purposes. Aristotle asserts that music can be engaged in as an amusement because 'amusement is for the sake of relaxation, and relaxation is of necessity pleasant, since it is a sort of cure for the pain caused by one's exertions' (Pol. 1339b15-17). It is important to see that, in this case, the 'for the sake of' relationship (marked in Greek by pros) is not one of means but of constitution. Pleasure brings about relaxation because pleasure just is the kind of movement of the soul that is relaxation (1337b42-1338a1). Amusements or harmless pleasures are well suited for this role since they are precisely those activities that one finds, as such, pleasant and that do not, in fact, have any further consequences besides being pleasant. Thus, when one decides to play guitar or listen to a musical piece, the relaxation is not something over and above the activity of playing or listening - one relaxes in that one enjoys playing or listening.

But there are other activities besides amusements that are not only pleasant, but also fine or useful. Shouldn't the virtuous agent choose those for relaxation instead of the trivial harmless pleasures of amusements? Aristotle appears to think that pleasant amusements are suited for relaxation in ways in which other pleasant activities are not. As he conceives of it, human beings have a built-in tendency to tire of things, whether physically or psychologically, and this weariness is best counter-balanced by relaxation through amusements. This view is perhaps best expressed in the following passage:

And blessedly happy people do not need anything useful, but do need pleasures. For they wish to live together with some companions, and although what is painful lasts for a short time, no one can continuously endure even the Good itself if it should be painful to him. That is why they seek friends who are pleasant. $(E N 1158 \mathrm{a} 23-26)^{22}$

The basic idea is that prolonged attention and focus on one thing, even if that thing should be the best and most rewarding, leads to fatigue and pain and a consequent inability to continue in one's current activities. This fatigue can only be remedied by a change of one's activity - by taking a break, as it were, to do something different, something that one, even in such condition, finds

\footnotetext{
${ }^{22}$ For similar claims see also EN 1175a5-10; De Somno 454a24-b9 and 455b13-29.
} 
genuinely pleasant. But in order to find that kind of pleasure, one's mind needs to turn away from the activities and concerns that one now finds painful.

The similarity that harmless pleasures bear to happiness makes them perfectly suited for this task, for taking one my mind's away from any (future or present) worries. One can treat them, at least for a certain period of time, as if they were happiness and, in that way and for that period of time, act as if there was no future work to be done. We often speak of one's ability to relax and when we do, we often mean that some people are better than others in taking their mind away from future (or even present) toils or problems, better at forgetting them for a while. It is no accident Aristotle mentions music in connection with relaxation. Music - especially engaging in it actively - is often thought to be an excellent way of relaxing since it tends, among other things, to divert one's attention fully to itself. ${ }^{23}$ This is crucial. It is plausible to think that choosing to relax explicitly so that one might work again could very well undermine one's relaxation since it would introduce elements that would diminish one's pleasant experience. First it would keep one mind intent on that which one currently finds painful (i.e., one's thoughts would be concerned with the future). Second, it would mean that one would treat one's relaxation as mere means. ${ }^{24}$ But, as Plato already recognized, if something is treated as a mere means, it itself becomes burdensome (Rep. 357b-c) since it does not correspond to any desire one has. ${ }^{25}$ Plato's thought here is psychological. Even though one might have reasons - even very good and decisive reasons for doing something that one finds is a means to some end that one desires, one might well find the means - considered in itself - unappealing and burdensome and so fail to desire it (some, but not all, cases of this sort would be cases of laziness). ${ }^{26}$ Hence, if one is to relax properly, one must treat one's relaxing activities as ends in themselves, and not as means to anything else. And one can best relax if one treats one's activities as complete ends. In

\footnotetext{
${ }^{23}$ The relaxing and therapeutic effects of music are well-known and have been researched throughout history. There are several journals (such as Journal of Music Therapy or Music Therapy Research) devoted to studying music as a relaxation technique.

${ }^{24}$ For a discussion of the paradox of inability to relax when explicitly trying to do so in order to relieve stress or fatigue, see Wegner, Broome, and Blumberg 1997, as well as Wegner 1997.

${ }^{25}$ Rep. 367b-c.

${ }^{26}$ In other words, there is nothing particularly strange about, say, wanting a bowl of soup but finding it too unpleasant or burdensome to make or buy one and so not coming to have a desire for the means to a given desired end. Compare to Schroeder 2009 who finds generation of instrumental desires 'little mystery', at least for rational agents, since they are obviously and unproblematically generated by the process of means-end reasoning starting from intrinsic desires (i.e., from desires for ends).
} 
other words, to the extent that one would keep one's mind focused on future goals (goals whose pursuit one currently finds painful), one's current enjoyment and so one's relaxation would be diminished. Relaxation must be done simply for the sake of pleasure. ${ }^{27}$ Harmless pleasures, as pleasant amusements, are best suited for this role.

A possible objection to this line of though could suggest that deciding on some pleasure for the sake relaxation (which we engage in in order to later engage in something serious later) is not problematic since we can decide explicitly so as to take a break or get unstressed but then once we engage in the pleasure (say, having a cup of tea) we simply attend to the pleasure (or to what we're doing in it) rather than (or not) to the reason why we made the decision. This objection has two problems. First, it assumes that that we can control our attention so that we do not focus on the reason why we do something. It might well be that we can do something like this (although it is not obvious that we can). But the problem is not what we think or have reasons to believe we can do, but how Aristotle's theory can explain and/or provide space for certain, intuitively useful (and recognized as such by Aristotle) ways of acting. Second, the argument does not require that anytime the virtuous agent decides to engage in some relaxing activity, she must do so without explicitly thinking about the real grounds for relaxing (i.e., future toils). All it requires is that this is a plausible and reasonable way in which one can or should relax and that that way is available to the virtuous agent.

If my argument so far is correct, there is a split between the objective role of harmless pleasures in a good life and the subjective attitude with which they need to be engaged in if they are to fulfill that role. Their objective role lies in their ability to relax us from past toils and enabling us to engage in serious actions and work again (1176b33). But we do not typically choose them with a view to this role. In fact, it would be a mistake to do so. Rather, we choose them for their own sake and it is precisely when we choose them in that way, that they can best fulfill their objective role. Aristotle compares the effects of amusements to that of medicine (1337b40-41) but there are important differences between the ways in which medicine and relaxation work. The effect of medicines is independent of one's intentions or state of mind in taking them - one's headache is diminished whether or not one takes a pill as a mere means to headache relief or, for some reason, as an end. But the success of relaxing activities depends on

\footnotetext{
${ }^{27}$ See Pol. 1339b20-25 translated above.
} 
the manner in which they are taken - they work best (or at all) only if performed for their own sake. It is this feature of relaxation that makes pleasant amusements eminently suitable for it they are activities that we naturally choose to do for their own sake and not being useful for anything else, they have little to no potential to distract one's mind in the wrong direction. ${ }^{28}$

In Aristotle's view, then, although virtue (and true happiness) is the more choiceworthy end, there are occasions when relaxation or amusements become the more suitable activities. In other words, even though study and virtue are better and, in general, more pleasant for the virtuous person, one cannot engage in them in the right way continuously. It is in such situations when we cannot anymore engage in serious activities that harmless pleasures become choiceworthy. I conclude that Aristotle thinks that there are activities that provide harmless pleasures and that even virtuous agents sometimes engage in them and when they do, they do so simply for the sake of the pleasure these activities offer.

\section{Harmless Pleasures and Decision}

If my argument has been correct, Aristotle thinks that virtuous agents sometimes pursue harmless pleasures for their own sake. This seemingly innocuous conclusion leads to an interesting problem in Aristotle's theory of decision. As usually understood, decisions result from deliberation about what action would best promote an end which is desired because it is being conceived of as good by the agent, an end which is the object of the rational kind of desire that Aristotle calls wish. But however one conceives of wishes, it turns out that, in the case of the virtuous agent, her set of rational desires or wishes cannot provide sufficient motivation for her to decide to pursue these pleasures.

Consider the view according to which the rational desires of at least the virtuous agent are grounded in her conception of eudaimonia. ${ }^{29}$ Harmless pleasures are neither constitutive nor

\footnotetext{
${ }^{28}$ Aristotle does not explicitly offer this explanation. I offer it as the best way of making sense of Aristotle's claims about pleasant amusements and harmless pleasures and their relation to relaxation and the human good.

${ }^{29}$ This view seems to be expressed at $E N$ 1176b31-32. It also seems to be implied by Aristotle's discussions in $E N$ 1.2 and 1.7, where Aristotle discusses eudaimonia as the highest goal of our actions. There are disagreements about how this 'grounding' of wishes in eudaimonia is supposed to work since there are disagreements about what it means to possess a conception of eudaimonia. On some views, one needs to have an explicit conception of eudaimonia (say, in the form of some general principles that determine what is good and bad). On a view of this sort, one comes to have a wish for something when one considers it as promoting one's eudaimonia. See, for example, Irwin 2007, 174; Cooper 1987. On other views, one's conception of eudaimonia need not be explicit (it could be, for example, an ingrained set of practices and valued) and one's wishes, although based on reasons one
} 
instrumental to eudaimonia. One's good life is neither enhanced nor hindered by engaging in them. Thus from the point of view of her wishes, the virtuous agent has no reason to prefer harmless pleasure to other, better activities which would enhance her pursuit of the good life. The same argument holds also for the view according to which wishes (even of virtuous agents) are based on reasons even if they are not, ultimately, grounded in one's conception of eudaimonia. The virtuous agent will always have more reasons - insofar as her rational desires are concerned - to pursue activities that are not just pleasant but also fine or useful than to pursue activities that are merely pleasant. Consequently, her rational desires alone cannot explain why she did or does decide to pursue them since insofar as they are concerned, they would always point to some other, finer or more useful, activity the virtuous agent could or should do.

Similarly, on a view of wish defended recently by Giles Pearson, ${ }^{30}$ according to which wishes are desires attached to serious human concerns, the virtuous agent would have no reason - insofar as her wishes are concerned - to pursue something as trivial as harmless pleasures. On all these views, then, it follows that the virtuous agent cannot decide (i.e., form a prohairesis) to go for harmless pleasures as such (i.e., as just pleasures). Decisions embody the agent's decisive reasons for taking an action on which she decides, and no such decisive reasons can be found in her set of rational desires. One could state the problem in the following way. The standard picture of decision maintains that in all cases of decision, one can reconstruct one's decisionmaking process as deliberation that starts from a wish that both specifies the goal and provides motivation to pursue it and ends in a specification of an action to be taken in order to promote or reach the goal. The problem is that, on most interpretations of wish, in the case of decisions of virtuous agents in which they decide to pursue harmless pleasures, such reconstruction is not possible since there is no wish (i.e., a rational desire) which could play the requisite role.

In response, one could maintain that one indeed cannot decide (in the technical, Aristotelian sense) to go for what is solely a harmless pleasure. But as I will argue in the next section below, this view is untenable. Another alternative is to modify one's conception of wish in such a way that it ceases to be a desire independent of one's perception of pleasure. This strategy has been recently proposed by Jessica Moss. ${ }^{31}$ On her view, wishes are still

would have for thinking that what one wishes for is good, would only need to be consistent or reflective of one's conception of eudaimonia rather than considered explicitly as promoting it. See, Mele 1981.

${ }^{30}$ Pearson 2012, 150-152.

${ }^{31}$ Moss 2012. I discuss further aspects of her view in section 4, under objection 2. 
distinguished from non-rational appetites insofar as the former, but not the latter, are based on a belief about the goodness of their objects. But on her view, to believe that something is good is not connected to having reasons for thinking that it is good but, rather, to assenting to an appearance of something as good. Although such assent requires that one conceptualizes the desired object as an end or goal for oneself, it does not require that one thinks that the object is good on the basis of some reasons, over above the appearance. ${ }^{32}$ Moss thus can offer a story about the way in which virtues of character contribute to decisions - they supply the correct beliefs since they are responsible for things appearing as good to the agent. However, since the appearance or phantasia of something as good is explained by Moss in terms of perceptual pleasure (i.e., to appear good is to appear pleasant), her view has the consequence (one that she embraces) that one can only decide to do what one finds pleasant: 'one can decide only on options one has pleasurably imagined'. ${ }^{33}$ But her view comes at a high price since we have to accept her argument that things can appear perceptually as good even to non-rational animals. This is a very difficult strategy to take since it requires one to re-interpret many explicit assertions of Aristotle to the contrary. ${ }^{34}$

A less demanding alternative is to abandon the standard view of decision and allow nonrational desires to be part of decisions. The argument is as follows. Given Aristotle's assumptions about wish and harmless pleasures, one cannot understand a virtuous agent's decision to pursue harmless pleasures independently of her non-rational desires or appetites. Of course, one can have a wish to satisfy one's appetites whenever appropriate. But this wish is not sufficient to move one to pursue harmless pleasures without there being the relevant non-rational desire: one would have no reason to act if one did not have it (i.e., if one did not feel like it). In other words, one cannot reconstruct the virtuous agent decision-making process (in which she decides to pursue some harmless pleasure) without reference to her relevant non-rational desires. Since the agent could not have reached her decision to pursue some harmless pleasure without an appropriate non-rational desire to motivate the decision, the decision must be motivated, and so must include, the non-rational desire as part of its desiderative element.

\footnotetext{
${ }^{32}$ Ibid., 37

${ }^{33}$ Ibid., 149.

${ }^{34}$ For a criticism of her view, see Corcilius 2011, 122-127.
} 
It is important to distinguish this case from one in which the action that one feels like doing turns out to be also one that one should do given that one wishes to promote one's eudaimonia or act virtuously. For example, one can feel like helping someone in need and subsequently discover that doing so is also what virtue requires of one. In this case, one can be said to act out of two distinct sets of reasons since each of those sets could, in principle at least, explain the action on its own. One can see the action as the result of one's feeling (thus we can imagine a person who acts simply because he feels like it), or one can see it as the result of one's realization about what generosity requires of one whether or not one feels like it. But such neat division is not available in the case of the virtuous agent's decision in favor of an action aimed at a harmless pleasure. It would seem, then, that if it is a genuine option for the virtuous agent to decide to decide to pursue some harmless pleasures, the standard interpretation of Aristotle's conception of decision cannot be right. One must allow that non-rational desires can contribute to the motivational force of decisions themselves. The question is, of course, whether the alternative view can be defended and supported by textual evidence that would make it possible. This is the task of the next section.

\section{Objections and Elaborations}

Objection 1: We do not decide, in the technical sense of the term, on harmless pleasures

One could object that the virtuous person's choice to pursue harmless pleasures of the kind I have described is not a decision (i.e., a $\pi \rho 0 \alpha i ́ \rho \varepsilon \sigma 1 \varsigma)$ in Aristotle's technical sense of the term. The reasoning might go as follows. Decisions are the results of deliberation and deliberation is about what is good and bad for human beings (EN 1142b29-35). Since the virtuous agent has organized her life around the pursuit of eudaimonia, her good deliberation is about what would best promote her eudaimonia. Since harmless pleasures neither contribute to

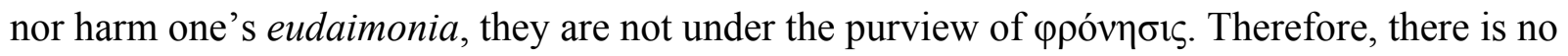
deliberation about them, and so also no decision. One can perhaps engage in some sort of technical calculation about them, but the choice one makes (to pursue some particular activity of harmless pleasure) is not a decision, since it is merely technical, and not tied to one's moral character. As Anscombe says, 'there is no such thing as a choice that is only technical'. ${ }^{35}$

\footnotetext{
35 Anscombe 1965, 146. Anscombe's that decisions are never merely 'technical' has been adopted by a number of scholars. Recently, see Frede 2008, 112. For a dissenting view, see Charles 1984.
} 
This worry presupposes that only reasoning in which one engages in order to determine how to promote one's eudaimonia counts as deliberation. It thus restricts what counts as deliberation as well as what counts as decision on the basis of the presence or lack of ethically significant content. Here it is sufficient to note that Aristotle clearly recognizes a class of technical decisions which are result of deliberation about how to promote some particular ends (1142b29-35). These decisions are not informed by one's character, but they are also not the results of deliberations about any objects of non-rational desires (as is the deliberation of the uncontrolled agent). A doctor might need to decide what to do in order to cure a patient, and he might well need to deliberate before making a decision about it. Such deliberation and decision can be entirely technical (based strictly on the considerations of efficiency). There is nothing in Aristotle's writings that would disqualify it as a prohairesis. In fact it is the prime example of what counts as deliberation and, hence, as decision. ${ }^{36}$

The technical decisions are based on considerations of goodness. For example, in the case of the doctor and the patient, they are based on considerations of the goodness of the patient's health. However, they are not based (ordinarily, at any rate) on considerations of what would promote the doctor's or even the patient's happiness. It might well be true that curing the patient is in the interest of the doctor (in the general sense in which being a good doctor is), but there is no reason to think that this interest has to figure in her deliberation. Similarly, it might well be that becoming healthy would promote the patient's happiness, but the doctor does not, ordinarily, deliberate about that either. Moreover, even assuming that the doctor is a virtuous person, it

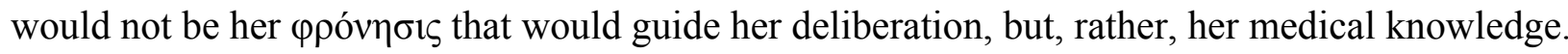

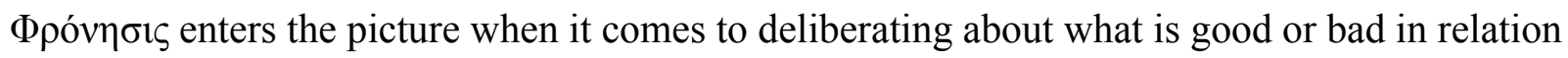
to one's good life in general. ${ }^{37}$ But that does not mean that one cannot deliberate and make decisions in some restricted areas. ${ }^{38}$

But perhaps the case of technical decisions is not relevant since they are, after all, clearly rooted in some sort of rational desire and are the products of deliberation. But can a choice (or an impulse) to relax be thought of in a way that would qualify it as a decision? One way to address this worry would be to claim that the virtuous person does everything from decision. But this

\footnotetext{
${ }^{36}$ See $E N$ 1112b1-10 where Aristotle talks about deliberation in money-making, medicine, and navigation.

${ }^{37}$ See $E N$ 1140a26-30; 1142b29-35.

${ }^{38}$ For this point see also Charles 1984, 152.
} 
cannot be true since not only does Aristotle say that some things we do voluntarily are not done from decision (NE 1112a14-17) (since they made be done on the spur of a moment), but also that there are complex things we do which do not require deliberation and, hence, do not require and are not done, on decision (NE 1112b1-9). Another, more persuasive, way to answer the worry would be to point to a passage in which Aristotle mentions or discusses a decision to engage in some relaxation or amusement. There is, however, no such explicit passage. Nevertheless, there are I think solid grounds for thinking that such decisions are part of the virtuous person's life.

First, in Aristotle's terminology, one usually does not decide (i.e., make a prohairesis) to relax or amuse oneself but, rather, one decides to engage in some particular activity (such as music, walking, or drinking coffee) in order to relax or amuse oneself. Relaxation and amusement are ends rather than things (actions) that contribute to ends. That is why some people (mistakenly) even make them 'the end' (Pol. 139b31-41; EN 1176b7-19). Once one adopts or desires to relax or amuse oneself, one can go on to deliberate about how to best achieve it. Thus just like one can decide to walk for the sake of health, one can also decide to walk for the pleasure of walking. ${ }^{39}$ In fact, walking would be the kind of relaxation that the virtuous person would prefer since it is, after all, healthier than, say, having a cup of coffee and a cigarette. ${ }^{40}$

Second, in order to initiate deliberation or thinking about how best to relax, one need not attend to relaxation or amusement as to one's end on the basis of anything further than one's feeling like relaxing or having fun. Aristotle allows that human beings can deliberate about how to achieve things for which they have merely an appetite (or a spirited desire) even while these desires do not conform to or are rooted in one's conception of eudaimonia. ${ }^{41}$ All desires are for ends ( $D A 3.10 .433 \mathrm{a} 15-16)$ and it is ends that we deliberate about how to achieve (rather than ends desired in some specific way). When Aristotle discusses deliberation in EN 3.3, he clearly asserts that, if it is successful, it ends in decision (1113a4-5) and it seems reasonable to understand Aristotle as saying that any desire for action determined by deliberation is decision. ${ }^{42}$

\footnotetext{
${ }^{39}$ EE 1226a8-9 together with Pol. 1339b31-41.

${ }^{40}$ EE 1222a29-34.

${ }^{41}$ This is clear at EN 1142b18-22: 'For the uncontrolled, or the vicious person, will reach what he proposes by calculation, and so will have deliberated correctly, but he will have got himself a great evil. But having deliberated well seems to be some sort of good; for this sort of correctness of deliberation is good deliberation, i.e. one that reaches a good.' See also EN 7.8.1151a1-5.

${ }^{42}$ For example: 'What we deliberate about is the same as what we decide on, except that what we decide on is already definite. For what we have judged as a result of deliberation is what we decide on' (EN 3.3.1113a2-4).
} 
This solution would require that the agent starts from a non-rational desire (say, for a cup of tea) and then proceeds to check, on the basis of some general wish to satisfy one's appetites, if satisfying the desire conflicts with one's eudaimonia or other (rationally-adopted) commitments. This procedure would then result in a decision which would aim at some good, but not a good which is a part of (or, at any rate, grounded in) eudaimonia but, rather, a good which is simply pleasure. Is there any evidence for a deliberative procedure of this sort in Aristotle? In the next section, I will provide evidence for thinking that Aristotle is not only aware that such deliberation exists but that he also explicitly discusses it.

Objection 2: No evidence for deliberation of the sort required for decisions concerning harmless pleasures

Aristotle has often been seen as not allowing, in his explicit conception of deliberation, anything other than straight calculation of the steps which lead to one's goal without any regard to any other, conflicting goals one might have. On the other hand, some interpreters of Aristotle assume (without any argument) that Aristotle allows for deliberation of this sort presumably because it seems obvious that we do think or deliberate in this manner. But the issue is not whether we think such deliberation exists, but whether his theory can provide space for it and although his theory of deliberation as explained in $N E 3.3$ is not incompatible with such procedure, it does not seem to consider it as an option. However, Aristotle does in fact describe, in at least two passages, deliberation which starts from a non-rational desire and is sensitive, in the right way, to one's rationally adopted ends. These passages are in important piece of evidence for the view of decision I have been defending. The first passage comes from his discussion of temperance:

The temperate person is in an intermediate state concerning these [bodily pleasures]. For he does not find pleasure at all in those things that the intemperate person finds most pleasure in, but is displeased by them, nor does he find pleasure at all in things that one shouldn't, nor extreme pleasure in anything of such a kind, nor does he feel pain or appetite when such things are absent, or only moderately so, not more than one should, and not when one shouldn't, nor in general anything of that sort. But those pleasant 
things that are conducive to health and fitness, he will desire moderately and in the right way, as he will also other pleasures if they are not obstacles to these [health and fitness]

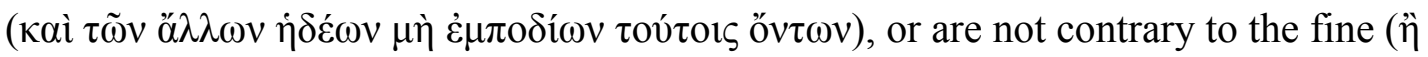

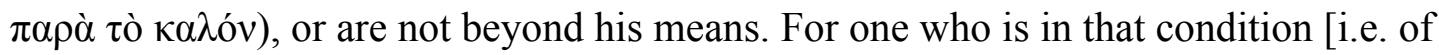
desiring these pleasures without regard to these considerations] likes such pleasures more than they are worth. But the temperate person is not of this sort, but [he likes them] in the way correct reason prescribes. (EN 1119a11-20)

This passage can be understood as describing the way in which the virtuous agent's nonrational are desire are conditioned with respect to the kinds of things or pleasures with which temperance is concerned. This is, of course, a plausible reading of the passage. However, finding out whether something one feels like doing (or having) is an obstacle to health, or contrary to the fine, or beyond one's means would often require deliberation or calculation since, presumably, it is not always clear whether or not doing something is of that sort. Since virtue is defined as issuing in decisions, that is, since making decision with regard to his feelings and bodily pleasures is something that the virtuous agent will (want to) do rather than simply letting herself go along with her feelings, ${ }^{43}$ the passage should be read not only as describing the way the virtuous agent's non-rational desires are conditioned, but also as a description of certain features of the virtuous agent's deliberation about pursuing various pleasures or, in other words, about acting on her non-rational desires.

If read in that way, the passage suggests that once a non-rational desire is aroused, the agent asks herself whether acting on it is also good (i.e., whether it is conducive to some relevant ends he has or, in general, conducive to his happiness), or at least harmless. The agent decides to pursue the pleasure only if she can answer affirmatively. As the passage makes clear, the virtuous agent employs considerations of various relevant ends in thinking about whether to act on the appetitive desires. She considers and takes into account these ends because she has adopted them as her ends, i.e., at the very least, formed rational desires for them. Rational desires

\footnotetext{
${ }^{43}$ This is very explicit in the following passage in the $E E$ : 'For example, when it comes to bodily exercise excess is healthier than deficiency and closer to the mean, but in the case of nourishment deficiency [is healthier] than excess.

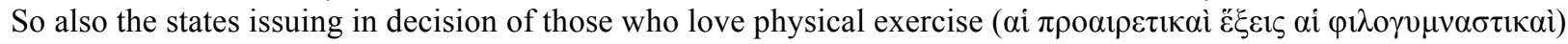

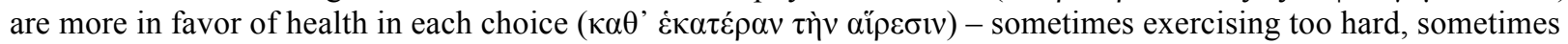
being more than firm [in abstaining from food]' (1222a29-34).
} 
thus play a crucial role in this process insofar as they act as a filter through which the agent's non-rational desires must pass in order to be acted on. It is noteworthy that in order to be initiated this process does not require that the agent has a rational desire for the object of her initial appetite. All that the process requires is that there is some general (perhaps even implicit) wish to act on one's non-rational desires provided there are no rational objections to so acting. This wish is enough to guarantee that the agent, once he has some appetite, starts the deliberative process. $^{44}$

A similar process is described in Aristotle's discussion of the nameless virtue that might be called friendliness in $N E$ 4.6:

We have said, then, that he will deal with people in the right way, aiming not to cause

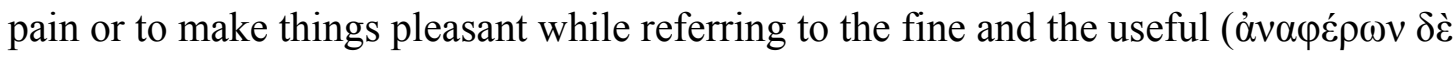

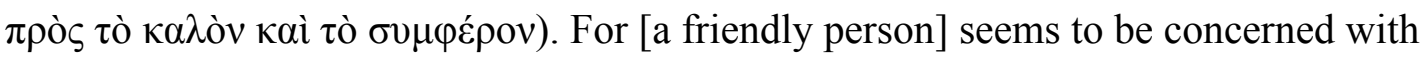
pleasures and pains that arise in dealing with people: but when it is not fine for him, or it is harmful, to make things pleasant, he will be annoyed and will decide to cause pain

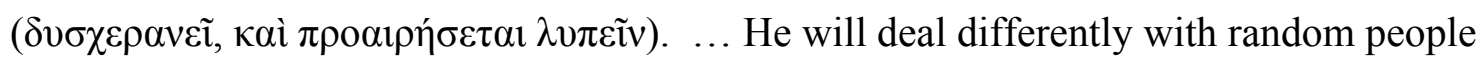
and with those worthy of honor, and so also with those he knows better and those he knows less well, and similarly with the other differences, assigning to each kind of person

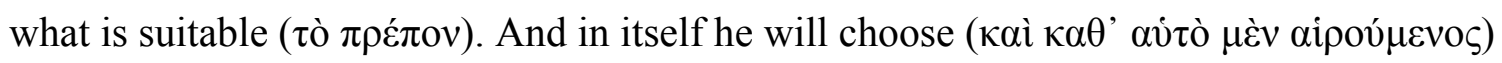
to make things pleasant and avoid causing pain, but in compliance with the consequences, if they are greater (

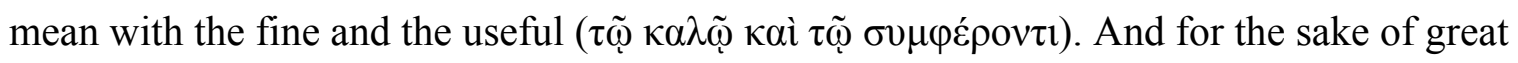
pleasure later, he will cause small pain. (1126b28-27a6)

The passage identifies the goal of the virtuous (in this case, the friendly) person's action, namely making things (for others) pleasant and avoiding causing pain and distinguishes it from the reasons that the agent might have for or against trying to satisfy that goal. Whether or not one should go for the goal (i.e., whether or not one's desire is to be satisfied) depends, on the one

\footnotetext{
${ }^{44}$ The context of the passage does not deal with actions aimed at harmless pleasures but, rather, with actions aimed at bodily pleasures with which the virtue of temperance is concerned. However, nothing in the passage prevents the reader from adopting for the case of harmless pleasures.
} 
hand, on one's particular situation and, on the other hand, on the considerations concerning 'the fine and the useful', as it also did in the previous passage. These considerations determine both how the goal can be achieved as well as whether it should be achieved at all. Notice that just like in the previous passage the initial desire for the goal can itself be a reason but only provided that it such that it is not outweighed by other relevant considerations.

The passages just quoted could suggest that Aristotle conceives of decisions in a similar way in which the Stoics conceived of assents - namely as rational acts of acceptance or rejection of impressions which suggest, but do not necessitate a course of action. This conception of Aristotelian decision has been recently endorsed, for example, by Jessica Moss. ${ }^{45}$ She writes:

The belief that one particular thing is to be done, the belief that is the conclusion of the practical syllogism, and the cognitive basis or component of a decision, is something like an assent to an evaluative appearance - an assent to a single phantasma generated through deliberation. ${ }^{46}$

This conception of decision could find support not only in the passages from Aristotle's discussion of temperance and friendliness quoted above, but also in a highly interesting passage from Aristotle's discussion of lack of control in the Magna Moralia:

It is not simply the case, as others think, that reason (ó $\lambda$ ó $о \varsigma$ ) is the principle and guide

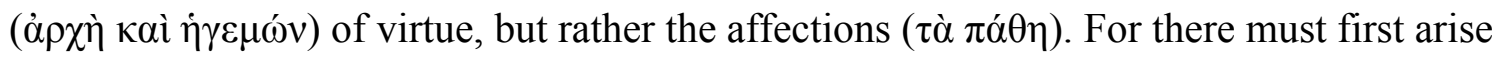

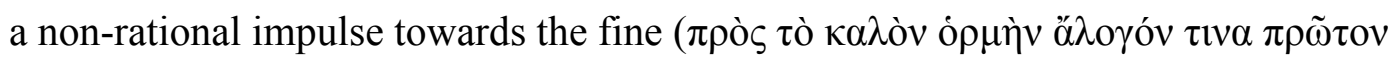

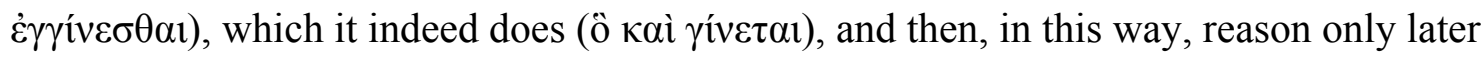

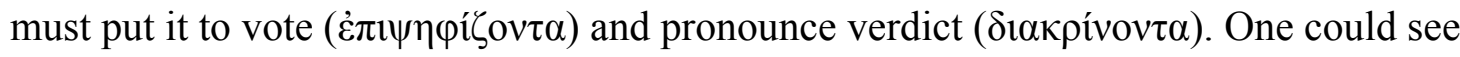
this from the case of children and those living without reason. For in these, there first

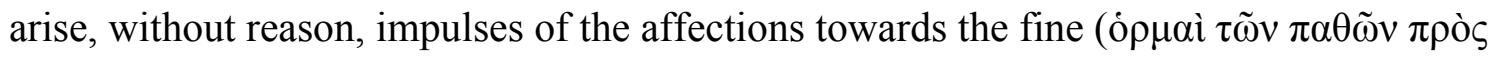
$\tau$ ¿ò $\kappa \alpha \lambda$ òv $\pi \rho o ́ \tau \varepsilon \rho \circ v)$, and reason comes only later and by voting approvingly ( $\sigma u ́ \mu \psi \eta \varphi о \varsigma$

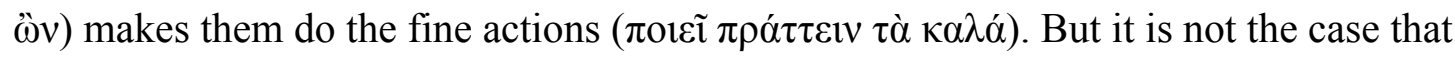

\footnotetext{
${ }^{45}$ Moss 2012, 112-18 and 142-52.

${ }^{46}$ Ibid., 149.
} 
when the principle towards the fine actions is received from reason, the affections follow it while consenting to it. Rather, they often oppose it. (MM 1206b17-28)

The passage is striking for its prima facie resemblance to some aspects of Stoic psychology. ${ }^{47}$ There are, of course, some obvious problems with the passage. First, it is a passage from the Magna Moralia and so it cannot be cited, insofar as scholarly consensus is concerned, as primary evidence for any of Aristotle's views. Second, the passage might be interpreted not as an account of the way in which human beings, once developed, make (virtuous) decisions but, rather, as an account of the development of the ability to make such decisions. ${ }^{48}$

But even putting these worries aside, it is crucial to keep in mind that even if Aristotle has a space (and I have argued that he does) for decisions that are made as results of deliberating about initial emotional responses or non-rational desires, ${ }^{49}$ this does not mean that all decisions come about in this way. I have already, in discussing the previous objection, pointed to cases of technical decisions. All decisions are, of course, made with a view to some facts of the matter: say, in the case of a patient, with a view to his current state (say, he is suffering from hypothermia). But this does not mean that one has or needs to have a non-rational impulse towards some action. One can just have a wish to make the patient healthy and deliberate, in view of the facts, how to best achieve that goal. Similarly, for example, one can deliberate about what one should do in the few hours before giving an important presentation without having in fact any particular non-rational impulse to do anything. In fact, most if not all Aristotle's examples of deliberations start from such general wished-for ends rather than from yet undetermined (and to that extent general) impulses (i.e., ones that need to be made specific) towards some actions (say, from an impulse to give money to charity). It is quite plausible to think that when it comes to long-term planning and to decisions about one's long-term plans, we rarely, if ever, start from non-rational impulses. It thus seems to me a mistake to attribute to Aristotle a conception of decision that restricts decisions to assents to non-rational impulses or

\footnotetext{
${ }^{47}$ So much that Susemihl thought that 'as others think' must refer to the Stoics: 'Verumtamen oi $\alpha 2 \lambda \lambda$ or $1206 \mathrm{~b}, 18$. reapse videntur Stoici esse' (Susemihl 1883, xii). On the other hand, Dirlmeier 1979, ad loc., identifies 'the others' with Socrates rather than with, as he think it was usual, members of the Old Academy.

${ }^{48}$ So Dirlmeier 1979, ad loc.

${ }^{49}$ This view is explicitly attributed to Aristotle by Korsgaard 1996.
} 
appearances, even if it is not a mistake to recognize that sometimes or perhaps often decisions are initiated by non-rational desires.

\section{Objection 3: Harmless pleasures are not objects of non-rational desires}

Yet another worry concerns the status of harmless pleasures as objects of non-rational desires. One might take the view that perhaps harmless pleasures - such as playing a game or listening to music - are not really objects of non-rational desires (i.e., of appetite or spirit) but, rather, objects of rational desires. ${ }^{50}$ This view is not without its merits. Some pleasures (and presumably also some harmless pleasures too, such as solving game puzzles) will belong to the rational soul and so might not result from any activities of sense-perception (e.g., $N E$ 1173b1619). In fact, sometimes Aristotle seems to restrict appetites to only pleasures arising out of touch and taste (and so to desires for drink, food, and sex). For example, in his discussion of temperance in the $E E$, he uses appetite to refer to such desires, preferring to speak of wishes when it comes to desires for looking at beautiful objects or for listening to music (1230b21-35).

In response, one can point out that normally Aristotle does not restrict appetites in the way just suggested. Rather, he simply defines appetite as a desire for pleasure $(D A 413 \mathrm{~b} 24$, 433b8, EE 1223a33, NE 1119a1-14, Rhet. 1370a17-71b1, Top. 146a36-b9) and, in particular, for pleasure which arises from perceptual activities quite in general. In fact, even the $E E$ passage (1230b21-35) cited above, he starts out by distinguishing between the appetites which are and those which are not the concern of temperance and so it is open for him to maintain that there are appetites which are for pleasures associated with sight, hearing, or smell. Still, perhaps the idea is that one enjoys - and has an appetite for - objects of sight, hearing or smell only when these are connected with previous lacks or pains, such as hunger, thirst, or sexual desire. Harmless pleasures, however, cannot be of that sort sine they are not connected with such bodily lacks and so they are not objects of appetite (e.g., De Sensu 443b19-44a3).

It might be difficult to decide, in general, whether or not all harmless pleasures are object of non-rational desires. Nevertheless, it is clear that some harmless pleasures are of that sort. The pleasure of getting a relaxing massage or the pleasure of having a nice cup of coffee and a piece

\footnotetext{
${ }^{50}$ This worry was communicated to me Christine Korsgaard.
} 
of cake are pleasures associated with touch and taste and so, even on the narrow understanding of Aristotle's conception of appetite, they would be objects of appetitive desires.

\section{Objection 4: No distinction between the uncontrolled agent's uncontrolled impulse and decision}

Another worry is that an interpretation of Aristotle's theory of decision that would allow non-rational desires to play a part in the decisions themselves, would lose a way to distinguish the uncontrolled agent's impulse for his uncontrolled action from a decision (i.e., that we would lose what was gained by accepting Anscombe's interpretation in the first place). The uncontrolled impulse is supposed to differ from a decision in that the agent does not aim by it at anything that she conceives of as being good (i.e., conducive to his eudaimonia), whereas a decision always aims at something conceived of as good by her. Since a decision to go for some harmless pleasure does not aim at anything conceived of as good in the relevant way (i.e., as ultimately aiming at one's eudaimonia), it seems to be indistinguishable from an uncontrolled impulse. ${ }^{51}$ This worry can be easily removed. In the uncontrolled case, the initial non-rational desire does not pass through the filter of the rational desires (as it is in fact contrary to them) and the deliberation that issues in the uncontrolled impulse is one that is not sensitive to the restriction of one's rational ends or eudaimonia. Reason in fact does not contribute any motivational force to the uncontrolled impulse. The virtuous person's decision to pursue harmless pleasure, on the other hand, remains sensitive to one's rational concerns and is made with reason's approval. In fact, it is not intelligible without the involvement of a wish, even if that wish is just the general wish to satisfy one's appetites (just as it is not intelligible without the presence of those appetites). Decisions remain essentially rational states. Rational desires (wishes) still play a crucial role in the generation of any decision, though they are not always sufficient in themselves to initiate and conclude deliberation.

\section{Conclusion}

\footnotetext{
${ }^{51}$ Following Anscombe, this worry permeates much secondary literature. See, for example, Irwin 2001, 78. In her original solution, Anscombe proposed that in order to avoid a contradiction in Aristotle's theory (between his claim that the uncontrolled agent does not decide for his uncontrolled action and his claim that he can deliberate about how to achieve it), we need to adopt the view that only deliberation starting from a wish can result in decision. This avoids the contradiction since the uncontrolled agent does not wish to do what he does without control. However, all that is actually required to avoid the contradiction is making deliberations that end in decisions sensitive to one's rational desires even if they do not begin or are not based on rational desires, as I suggest above. See Müller 2015 for an account of uncontrolled actions that incorporates this idea.
} 
In conclusion, there are decisions that are primarily driven by non-rational desires. These decisions are still aimed at some good - but this good is, on the one hand, a mere pleasure (i.e., a pleasure which is not part of eudaimonia) and, on the other hand, simple non-interference with the pursuit of one's long-term wished-for ends. The main motivating factors in such decisions are non-rational desires (i.e., the fact that one enjoys something and feels like doing whatever it is that one decides to do). Somewhat metaphorically one could say that reason merely tags along with appetite, having no objections. The wish that is involved in the agent's decision to engage in these sorts of activities is only the general wish to satisfy one's non-rational desires provided their satisfaction does not interfere with the agent's eudaimonia. But the pursuit of this wish crucially depends on one's having and feeling an appetite in the first place.

In my argument, I did not discuss direct textual evidence for this view since much of what Aristotle says about decision, especially in $E N 3.2$ or $E E 2.10$, is subject to interpretation and compatible with a number of positions. However, there are in fact a few passages that can be summoned to support the idea directly. First, when Aristotle discusses, in EE 2.10, the nature of decision he starts by rejecting the idea that it is (just) a desire since 'it would then be either wish or appetite or spirit' (1225b25). He then goes on to support the idea that decision cannot be appetite or spirit by saying that 'many people decide without appetite or spirit' (1225b28-9). This clearly implies that some decisions are made with appetite or spirit. Second, although Aristotle argues that decision is a deliberative desire (orexis) (e.g., EN 1139a22-26), he never says that the desiderative element in it is a wish ${ }^{52}$ - in fact, he explicitly argues that decision is not a wish (EN $1111 \mathrm{~b} 20-31$; EE 1225b24-40) even if he at the same time says that wish is always present (1226b2-4). These claims are very much in harmony with the interpretation I outlined above according to which always plays a role in the formation of decision but decisions are not restricted to wishes. Rather, they can involve any of the three desires Aristotle recognizes as long as these desires have been 'processed' by deliberation guided by one's rationally adopted goals (wishes). This view also chimes well with Aristotle's claim that 'no one has a desire without

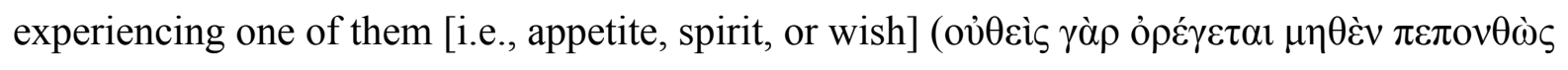
$\tau o v ́ \tau \omega v)$ ' (EE 1225b25-26). Decision, being an orexis, can involve experiencing any of its three kinds even if it has special connection to deliberation and wish.

\footnotetext{
${ }^{52}$ For a view (by no means unique) that explicitly identifies the desiderative aspect of decision with wish see Cooper $1989,247$.
} 
Third, Aristotle's account of excellent decisions in EN 6.2 seems to support the idea that excellent decisions require more than just wish and deliberation:

Now moral virtue is a state that issues in decision; and decision is a deliberative desire. If, then, the decision is excellent ( $\sigma \pi 00 \delta \alpha i \alpha)$, the reason must be true and the desire correct, so that what reason asserts is what desire pursues. (EN 1139a22-26)

In the passage, Aristotle says that excellent decision involves the agreement between (correct or true) reason and desire. ${ }^{53}$ It is possible to interpret the passage as asserting that there must be an agreement between reason and the rational kind of desire (i.e., wish). This is what Aristotle should be saying here if his conception of decision includes only wish as the relevant desiderative component. However, since wish is the desire that belongs to and originates in reason, it cannot disagree with reason. So on this interpretation, the passage advances a trivial and superfluous claim. In order to make the passage informative, it seems preferable to understand Aristotle as having in mind all desires, and in fact prominently non-rational desires. These desires can be in conflict with reason and, hence, not pursue what reason asserts. Interpreted this way, the passage tells us something important. Excellent decision involves the agreement between reason and non-rational desires. ${ }^{54}$

Although my argument requires that a correct account of decision must accommodate non-rational desires, it does not say anything about how this is to be achieved. In particular, what we need is an account of how appetite or spirit - the two non-rational kinds of desires - can, in the case of human beings, become parts of a unified psychological act that involves both rational and non-rational elements. This is, of course, the hard part, especially if one is to move beyond metaphorical language (such as Aristotle's favorite example of the unity of the convex and concave shapes) or mere assertions (such as that all human desires are, somehow, informed by rationality) and identify the features in virtue of which the various kinds of desires Aristotle recognizes can be thought of as, potentially, forming a unity. But this is a task for another time.

\footnotetext{
${ }^{53}$ I take it that by excellent decisions Aristotle means the correct decisions of the virtuous agent.

${ }^{54}$ The passage is understood in a similar way Richardson Lear 2004, n99.
} 


\section{BIBLIOGRAPHY}

Ackrill, J. L. 1974. 'Aristotle on Eudaimonia' 15-33 in A. O. Rorty ed. 1980. Essays on Aristotle's Ethics. Berkeley: University of California Press.

Anscombe, G.E.M. 1965. 'Thought and Action in Aristotle' 145-148 in R. Bambrough ed. New Essays on Plato and Aristotle. London: Routledge.

Bodeüs, Richard, trans. 2004. Aristote: Éthique à Nicomaque. Paris: GF Flammarion.

Bostock, David. 1998. 'Pleasure and Activity in Aristotle's Ethics' Phronesis 33: 251-272.

Broadie, Sarah. 1991. Ethics With Aristotle. New York: Oxford University Press.

Broadie, Sarah and Christopher J. Rowe. 2002. Aristotle: Nicomachean Ethics. Oxford: Oxford University Press.

Charles, David. 1984. Aristotle's Theory of Action. Ithaca: Cornell University Press.

Cooper, M. John. 1975. Reason and Human Good in Aristotle (Cambridge, Mass.: Harvard University Press.

Cooper, M. John. 1987. 'Contemplation and Happiness: A Reconsideration’ 212-236 in his 1999. Reason and Emotion: Essays on Ancient Moral Psychology and Ethical Theory. Princeton: Princeton University Press.

Cooper, M. John. 1989. 'Some Remarks on Aristotle’s Moral Psychology’ 237-252 in his 1999. Reason and Emotion: Essays on Ancient Moral Psychology and Ethical Theory. Princeton: Princeton University Press.

Cooper, M. John. 2009. 'Nicomachean Ethics VII 1-2: Introduction, Method, and Puzzles' 9-40 in C. Natali ed. Symposium Aristotelicum XII. Oxford: Oxford University Press.

Corcilius, Klaus. 2008. Streben und Bewegen: Aristoteles’ Theorie der animalischen Ortsbewegung. Berlin: Walter de Gruyter.

Corcilius, Klaus. 2011. 'Aristotle's definition of non-rational pleasure and pain and desire' 117143 in J. Miller ed. Aristotle's Nicomachean Ethics: A Critical Guide. Cambridge: Cambridge University Press.

Crisp. Roger. 1994. 'Aristotle's Inclusivism' Oxford Studies in Ancient Philosophy 12: 111-136.

Dirlmeier, Franz. 1966. Aristoteles: Nikomachische Ethik. Berlin: Akademie Verlag.

Dirlmeier, Franz. 1979. Aristoteles: Magna Moralia. Berlin: Akademie Verlag. 
Frede, Dorothea. 2008. 'Auf Taubenfüßen: über Natur und Ursprung des OР $\mathrm{O} \Sigma \Lambda \mathrm{OГО} \Sigma$ in der Aristotelischen Ethik' 105-122 in K. Corcilius and C. Rapp edd. Beiträge zur Aristotelischen Handlugstheorie. Stuttgart: Franz Steiner Verlag.

Gauthier, R. A. and J. Y. Jolif. 1958 L'Éthique à Nicomaque. 2nd ed. 1970. Louvain: Publications Universitaires.

Gourinat, Jean-Baptiste. 2002. 'Délibération et choix dans l'éthique aristotélicienne' 95-124 in G. Aubry and G. Romeyer Dherbey edd. L'excellence de la vie: sur l'Éthique à Nicomaque et l'Éthique à Eudème d'Aristote. Paris: Librarie Philosophique J. Vrin.

Hardie, W. F. R. 1968. Aristotle's Ethics Theory. 2nd edn. 1980. Oxford: Oxford University Press.

Irwin, Terence. 1975. 'Aristotle on Reason, Desire, and Virtue' The Journal of Philosophy 17: 567-578.

Irwin, Terence. 1988. Aristotle's First Principles. Oxford: Oxford University Press.

Irwin, Terence. 1985. Aristotle: Nicomachean Ethics. 2nd edn. 1999. Indianapolis: Hackett.

Irwin, Terence. 1985. 'Permanent Happiness: Aristotle and Solon' Oxford Studies in Ancient Philosophy 3: 89-124.

Irwin, Terence. 2001. 'Vice and Reason' The Journal of Ethics 5: 73-97.

Irwin, Terence. 2007. The Development of Ethics: A Historical and Critical Study. Oxford: Oxford University Press.

Kenny, Anthony. 1979. Aristotle's Theory of the Will. London: Routledge.

Kenny, Anthony. 1992. Aristotle on the Perfect Life. Oxford: Oxford University Press.

Korsgaard, Christine. 1996. 'From Duty and For the Sake of the Noble: Kant and Aristotle on Morally Good Action' 203-236 in S. Engstrom, and J. Whiting edd. Aristotle, Kant, and the Stoics: rethinking happiness and duty. New York: Cambridge University Press.

Kosman, L. A. 1980. 'Being Properly Affected: Virtues and Feelings in Aristotle's Ethics' 103116 in A. O. Rorty ed. Essays on Aristotle's Ethics. Berkeley: University of California Press. Kraut, Richard. 1989. Aristotle and the Human Good. Princeton: Princeton University Press. Long, Anthony. 2011. 'Aristotle on eudaimonia, nous, and divinity' 92-114 in J. Miller ed. Aristotle's Nicomachean Ethics: A Critical Guide. Cambridge: Cambridge University Press. Lorenz, Hendrik. 2009. 'Virtue of Character in Aristotle's Nicomachean Ethics' Oxford Studies in Ancient Philosophy 37: 177-212. 
Mele, Alfred. 1981. 'Choice and Virtue in the Nicomachean Ethics' Journal of the History of Philosophy 19: 405-423.

Moss, Jessica. 2012. Aristotle on the Apparent Good. Oxford: Oxford University Press.

Moss, Jessica. 2014. 'Was Aristotle a Humean? A Partisan Guide to the Debate' 221-241 in R. Polansky ed. Cambridge Companion to the Nicomachean Ethics. Cambridge: Cambridge University Press.

Müller, Jozef. 2015. 'Aristotle on Actions from Lack of Control' Philosopher's Imprint 15.8: 135.

Pearson, Giles. 2012. Aristotle on Desire. Cambridge: Cambridge University Press.

Reeve, C. D. C. 1992. Practices of Reason. Oxford: Oxford University Press.

Richardson Lear, Gabriel. 2004. Happy Lives and the Highest Good: an essay on Aristotle's Nicomachean Ethics. Princeton: Princeton University Press.

Schroeder, Timoty. 2009. 'Desire' in E. N. Zalta ed. 2014. The Stanford Encyclopedia of Philosophy. URL $=<$ http://plato.stanford.edu/archives/spr2014/entries/desire/>.

Segvić, Heda. 2009 'Deliberation and Choice in Aristotle' 144-171 in her M. Burnyeat ed. 2009. From Protagoras to Aristotle: Essays in Ancient Moral Philosophy. Princeton: Princeton University Press.

Shields, Christopher. 2011. 'Perfecting pleasures: the metaphysics of pleasure in Nicomachean Ethics X' 191-210 in J. Miller ed. Aristotle’s Nicomachean Ethics: A Critical Guide. Cambridge: Cambridge University Press.

Sorabji, Richard. 1980. 'Aristotle on the Role of Intellect in Virtue' 201-219 in A. O. Rorty ed. Essays on Aristotle's Ethics. Berkeley: University of California Press.

Susemihl, Franz. 1883. Aristotelis quae feruntur Magna moralia. Lepzig: Teubner.

Wegner, D.M. 1997. 'When the Antidote Is the Poison: Ironic Mental Control Processes' Psychological Science 8.3: 148-150.

Wegner, D.M., A. Broome and S.J. Blumberg. 1997. 'Ironic effects of trying to relax under stress' Behaviour Research and Therapy 35: 11-21.

Whiting, Jennifer. 1986. 'Human Nature and Intellectualism in Aristotle' Archiv für Geschichte der Philosophie 68: 70-95. 